\title{
Evaluation of the Effect of Fly Ash and Slag on the Properties of Cement Asphalt Mortar
}

\author{
Tri H. M. Le $\mathbb{D}^{1},{ }^{1}$ Dae-Wook Park $\left(\mathbb{D},{ }^{1}\right.$ Jin-Yong Park, ${ }^{2}$ and Tam M. Phan ${ }^{1}{ }^{1}$ \\ ${ }^{1}$ Dept. of Civil Engineering, Kunsan National University, 558 Daehak Ro, Jeonbuk, Republic of Korea \\ ${ }^{2}$ Korea Rail Network Authority, 242 Jungang-Ro, Dong Gu, Daejeon 34618, Republic of Korea \\ Correspondence should be addressed to Dae-Wook Park; dpark@kunsan.ac.kr
}

Received 25 March 2019; Accepted 26 June 2019; Published 10 July 2019

Guest Editor: Quantao Liu

Copyright (c) 2019 Tri H. M. Le et al. This is an open access article distributed under the Creative Commons Attribution License, which permits unrestricted use, distribution, and reproduction in any medium, provided the original work is properly cited.

The application of cement asphalt mortar (CAM) in modern high-speed railways has been gaining attention due to its combined merits between asphalt and cement hydration product characteristics. To promote sustainable development, it is promising to utilize by-products in the making of new CAM instead of using only cement. In this research, the cement content was partly replaced by fly ash or ground-granulated blast furnace (GGBS) slag to achieve this objective. Then, laboratory experiments were conducted to determine the effect of these admixtures on the fresh and hardened characteristics of CAM. The test results revealed that the CAM mixture with slag received better fresh properties compared to the controlled mixture. However, the poor pozzolanic property of these by-product materials may lead to the low strength development. Meanwhile, although the mixture with fly ash suffered from slow strength establishment compared to the control mix at an early age, the strength of this condition increases dramatically after 28 days. Based on the findings, the application of appropriate fly ash content in the CAM mixture will not only provide ideal workable time and mixing stability but also ensure the required strength for the design target. This combination also serves as a cost-effective and environmental solution.

\section{Introduction}

Progressive ballast deterioration and geometry degradation have been seriously impacting the performance of railway track systems associated with high traffic pressure. The weakening structure will impose critical safety effects on the track system and reduce the comfort of railway users. Recently, some innovative solutions have been proposed to solve this issue [1-4]. One of the rehabilitation strategies of ballast degradation is to reduce track vibration by using crumb rubber. However, tracks incorporated with this technique have suffered from high vertical settlement and low bearing capacity [4]. Another solution was introduced in the study of Kennedy et al. [5], in which the authors utilize geosynthetics in the ballast layer. It was noticed that injecting polyurethane into the ballast will not only improve the settlement resistance of the ballast structure but also ensure the railway structural integrity. However, the significantly high construction cost limits the wide application of this method.
In Japan and Europe, a cost-effective concept has been applied for decades to enhance the performance of the track system and reduce the maintenance effort [6-10]. In this method, cement asphalt mortar was utilized as an interlayer between the track slab and the concrete roadbed $[7,8]$. Reports indicated that stress dissipation characteristics from the asphalt membrane will reduce the pressure for the whole structure, thereby sustaining the long-time service life [7-10]. Meanwhile, the cement hydration product will ensure the vertical settlement resistance of the railway track. Another advantage of CAM is simple application with self-leveling behavior. The fresh material can be pumped without compaction machine support [7-10].

Also, the main components of CAM can be easily provided by the local construction company such as asphalt emulsion (AE), cement (C), sand (S), and water (W). However, this nonballast slab track method with CAM can only be applied at the initial stage of construction [6-10]. This drawback may hinder its application in actual ballast 
degradation rehabilitation projects. Therefore, this research objective is to generate a new strategy named "cement asphalt mortar-stabilized ballast" which not only can achieve the merits of the above nonballast method but can also be applied as a fouled ballast rehabilitation solution.

The present technique evaluates the possibility of stabilizing ballast with cement asphalt mortar, as a prominent solution to reduce the loss in track quality due to particle degradation and ballast settlement. By pouring fresh CAM above the ballast layer, the self-leveling CAM mixture will flow throughout the whole ballast system. The CAM mixture will coat the ballast particles and create strong bonding between them [3]. This bonding will achieve the stiffness from cement hydration products and viscoelasticity from the asphalt membrane [3]. It is expected that the connection between CAM and fouled ballast structure will behave as a new stress dissipation system with high rutting resistance. Moreover, due to the fast application with simple preparation, this technique will also save time for traffic closure.

Prior research about this technique has brought promising results for wide application. The preliminary test results show that optimum $\mathrm{C} / \mathrm{AE}$ ratios can propose a good mixture with both merits from asphalt and merits from cement hydration products [6-11]. The incorporation of sand and proper initial water will noticeably improve the mixing stability of the fresh CAM mixture which not only shortens the flow time but also contributes to the homogeneous distribution of CAM particles [11, 12]. Prior research also found that the application of quick-hardening admixture as a replacement of cement (14\%) provides fast strength gain at an early age without impact on the mixing stability characteristic [11].

In recent decades, research has demonstrated that fly ash can be applied in many structural applications, providing good mechanical properties and durability of concrete [13-16]. In the operation of thermal power plants, fly ash is collected by an electrostatic precipitator from the combustion of powdered coal. This by-product has been found to possess pozzolanic, hydraulic characteristics with glassy, spherical particles of finer size compared to cement [14].

The application of fly ash in cement mortar not only enhances the workability at an early age but also contributes to long-term strength gain of concrete [15]. Based on related research [13-16], it is suggested that the content of fly ash should be designed from 20 to $30 \%$ by weight of cement in concrete or mortar to achieve optimum performance. In massive structures (foundation, dams, etc.), reports suggest that higher levels of fly ash should be used (up to 50\%) to help control the thermal cracking. In the hydration process of cement, the internal temperature of concrete will be reduced remarkably by using fly ash, thereby lowering the temperature gap between inner and outer parts of concrete [15].

With regard to the use of fly ash in asphalt pavement, most recent studies have focused on the application of fly ash as a mineral filler for asphalt pavement [13]. The authors confirm that the incorporation of fly ash improves the performance of the asphalt mixture because of its unique spherical shape, beneficial particle size distribution, and chemical properties. Some studies show that these characteristics of fly ash enhance the workability and flexibility and improve the rutting and freeze-thaw resistance of asphalt concrete [16]. In the research of Ramme et al., the authors prove that the fatigue life and tensile strength of asphalt concrete can be slightly increased by using an appropriate amount of Class F fly ash [16]. Moreover, reports found that replacement of natural fillers by fly ash will provide better antistripping and moisture resistance properties for asphalt pavement because of the strong connection between fly ash hydration products and asphalt membrane [13, 16]. The findings of these demonstrations established the foundation for further study on the practical application of fly ash.

The application of GGBF slag in the production of the concrete mixture has been gaining attention recently through some important improvements in engineering properties [17-19]. From iron production, slag is defined as a nonmetallic by-product which is composed mainly of silicates of calcium. Compared to cement, the particles size of slag is much smaller (less than 45 microns) which provides noticeable improvements in the ease of concrete pumping and placement [18]. With appropriate mixing content, this mineral admixture can provide much better workability and enhance the durability of concrete by improving the interface with the cement hydration product. Slag shares relatively the same characteristic with fly ash that has both pozzolanic and cementitious properties [18].

Based on related research [17-19], this mineral admixture can significantly affect certain engineering characteristics of both fresh and hardened concrete [19]. By eliminating the amount of reactive element (such as calcium) needed for expansive sulfate reaction, GGBF slag can significantly protect concrete from sulfate attack. Also, reports confirmed that GGBF slag can reduce the potential of concrete to expand due to alkali-silica reaction [19]. Slagblended cement will provide ecological advantages by resource conservation to energy efficiency.

Recently, the investigation of CAM mechanical properties has gained attention from many research studies [6-10]. However, there has been lack of investigations as to the utilization of by-products in the production of CAM. Therefore, in this research, slag and fly ash will be first introduced as admixtures in the CAM mixture. The incorporation of the two by-products is expected to improve the fresh properties of CAM and long-time strength gain. The aim of the conducted research is to identify the influence of different dosages of fly ash or slag on the mechanical properties of CAM.

To acquire this objective, cement used in the CAM mixture was replaced by fly ash/slag with contents varying from $10 \%$ to $30 \%$ with an increment of $10 \%$. Based on preliminary research on obtaining efficient CAM mixtures, this research has asphalt emulsion/cement (AE/C), quickhardening admixture/cement (QA/C), and water/cement $(\mathrm{W} / \mathrm{C})$ ratios of $0.75,0.14$, and 0.5 , respectively. The behavior of the fresh CAM mixture was evaluated by conducting the flow cone test, mixing stability test, bleeding test, and workable time test. Then, the hardened stage of CAM was assessed by employing the unconfined compressive strength 
(UCS) test on the samples $2 \mathrm{~h}$ after casting them into molds and after 28 days. Finally, to identify the microstructure of hardened CAM after 28 days, the FEI Quanta 200F scanning electron microscopy (SEM) test was conducted on CAM samples.

\section{Materials and Test Methods}

Type II Portland cement was used in this study. Class F fly ash was provided by the Korean Western power plant, while GGBF slag was supplied by the Korean iron manufacturing company. The overall chemical properties of cement, fly ash, and slag are displayed in Table 1. The asphalt emulsion is of an anionic type with properties shown in Table 2. Presented in Table 3 is the mix design based on cement weight. The mixing water $(\mathrm{W})$ and asphalt emulsion (AE) contents were selected from the trial mixing test which produced ideal rheology performance at an early age. Based on the suggestion from related studies [10-12], when the fly ash or slag content is increased, less water should be used to ensure the stable workability of all mixtures. This study also incorporates the use of a quick-hardening admixture (QA) at a level of $14 \%$ by mass of cement based on a trial test to achieve the fast strength development and mitigate the bleeding phenomenon. In addition, the excessive air bubbles from asphalt emulsion are reduced by using $0.1 \%$ defoaming agent (D) (by weight of cement) [10-12]. The initial adding water was mixed with $2 \%$ polycarboxylate superplasticizer (SP) based on the author team's experience.

2.1. Mixing Method. Based on the authors' experience and after preliminary research $[10-12,20]$, the wet mixing method was employed in this research. In this method, solid contents (C, QA, and S) were premixed with a water + SP mixture to create the cementitious slurry. The mixing of the slurry was done for approximately 2 minutes at mixing rate of $120 \mathrm{rpm}$. Then, the $\mathrm{AE}+D$ mixture was then added into the cementitious slurry and mixed together for at least 3 minutes with a mixing rate of $60 \mathrm{rpm}$ before casting them into cylindrical test sample molds $(\varnothing 50 \times 100 \mathrm{~mm})$.

The $\mathrm{AE}+D$ mixture will improve the mixing stability of asphalt droplets in the asphalt emulsion. The demulsification process of the $\mathrm{AE}$ is mitigated, thereby developing a fresh CAM mixture with homogeneous particle sizes and with rare signs of agglomeration. With regard to the replacement of cement by slag or fly ash, this solid content was added into the initial premixed stage as cement.

2.2. Mixing Stability Test. Based on preliminary research suggestion, the CAM mixture should obtain proper mixing stability to achieve good flowability and homogeneous particle distribution without agglomeration phenomenon. Therefore, the mixing stability test is first conducted among all tests in this study (Figure 1(a)). Based on KSM 2203 [21], $50 \mathrm{~g}$ of asphalt emulsion (50\% solid) is poured into a can with $50 \mathrm{~g}$ dry cement. Then, the mixture is thoroughly mixed for around $2 \mathrm{~min}$ at a stirring rate of $120 \mathrm{rpm} .150 \mathrm{ml}$ of deionized water is then added to the mix and slowly stirred
TABle 1: Percentage chemical composition of cement, fly ash, and slag.

\begin{tabular}{lccccccc}
\hline $\begin{array}{l}\text { Chemical } \\
\text { composition (\%) }\end{array}$ & $\mathrm{SiO}_{2}$ & $\mathrm{Al}_{2} \mathrm{O}_{3}$ & $\mathrm{Fe}_{2} \mathrm{O}_{3}$ & $\mathrm{SO}_{3}$ & $\mathrm{CaO}$ & $\mathrm{MgO}$ & $\mathrm{K}_{2} \mathrm{O}$ \\
\hline Cement & 21.56 & 4.15 & 2.64 & 3.01 & 61.18 & 2.35 & 0.65 \\
Fly ash & 49.9 & 24.0 & 14.4 & 0.88 & 3.23 & 0.98 & 2.46 \\
Slag & 32.7 & 14.5 & 0.4 & 0.4 & 41.4 & 4.7 & 0.6 \\
\hline
\end{tabular}

at a rate of $60 \mathrm{rpm}$ in this second stage for additional $3 \mathrm{~min}$. Finally, the fresh mixture is poured through a $1.18 \mathrm{~mm}$ sieve to collect the remaining residue which will be oven-dried and weighted for calculating the mixing stability status:

$$
P_{\mathrm{r}}=\frac{m}{m_{1}+m_{2}} * 100 \%
$$

where $P_{\mathrm{r}}=$ percentage of the residue content, $m=$ ovendried weight of the residue retained on a $1.18 \mathrm{~mm}$ sieve $(\mathrm{g})$, $m_{1}=$ weight of asphalt $(\mathrm{g})$, and $m_{2}=$ weight of cement $(\mathrm{g})$.

In the optimum mixture, the CAM combination includes cement, asphalt emulsion, sand, water, superplasticizer, and defoaming agent. In preliminary research, the sand and water content will improve the stability of asphalt droplets in asphalt emulsion by lowering the adsorption energy of cement particles. It is predicted that the partial replacement of cement by fly ash or slag will also improve the mixing stability of the mixture. Hence, the new mixing stability was developed with the aim of focusing only on the reaction between cement, slag, and fly ash with asphalt emulsion. The mix design for this new test is shown in Table 4.

2.3. Flowability Test. One of the interesting merits of CAM is the self-leveling ability which allows this fresh material to be applied in a narrow place in a short time. Hence, the flow cone test is used to evaluate this characteristic in accordance with Korean Standard KSF 2432 [22]. In this test, a steel cone with a closed end nozzle, a steel plate $(50 \mathrm{~cm} \times 50 \mathrm{~cm})$, a digital watch with counting function, and $400 \mathrm{ml}$ of the fresh mixture are prepared. After thorough mixing, the flow time is determined by recording the required time for $400 \mathrm{ml}$ fresh CAM mixture to completely flow out from the steel cone to the steel plate (Figure 2).

2.4. Bleeding and Workable Time. Bleeding is one of the critical problems during the fresh stage of CAM mixtures which imposes segregation, reduces the initial shear stress in mortar, and retards the setting time of cement. The workable time in this research is defined as the amount of time in which the sample is able to retain an acceptable flowability similarly during the initial stage. After this period, the mixture hardens and could not be appropriately cast. In the research of Ouyang et al. [23], the cement hydration is significantly high in the initial $5 \mathrm{~min}$. In this period, the effect of cement on asphalt droplets is more prominent. However, after this time, the asphalt emulsion may be less impacted by the cement hydration process because of thermodynamic stability. Hence, the bleeding phenomenon is tracked after 
TABle 2: Properties of anionic asphalt emulsion.

\begin{tabular}{lccccc}
\hline $\begin{array}{l}\text { Density } \\
\left(\mathrm{g} / \mathrm{cm}^{3}\right)\end{array}$ & $\begin{array}{c}\text { 1-day storage stability } \\
(\%)\end{array}$ & $\begin{array}{c}\text { Residue after distillation } \\
(\%)\end{array}$ & $\begin{array}{c}\text { Residue on } 1.18 \mathrm{~mm} \\
\text { sieve }(\%)\end{array}$ & $\begin{array}{c}\text { Penetration depth at } \\
25^{\circ}(0.1 \mathrm{~mm})\end{array}$ & $\begin{array}{c}\text { Solid content } \\
(\%)\end{array}$ \\
\hline 1.02 & 0.3 & 50 & 0.01 & 70 & 50 \\
\hline
\end{tabular}

TABle 3: Mix design (by weight of cement/by weight of cement + by-product).

\begin{tabular}{|c|c|c|c|c|c|c|c|c|}
\hline & By-product & Cement (\%) & QA (\%) & $\mathrm{AE}(\%)$ & S (\%) & W (\%) & SP (\%) & $D(\%)$ \\
\hline $\mathrm{C}$ & 0 & 100 & 14 & 75 & 50 & 40 & 2 & 0.1 \\
\hline FA10 & 10 & 90 & 14 & 75 & 50 & 35 & 2 & 0.1 \\
\hline FA20 & 20 & 80 & 14 & 75 & 50 & 32.5 & 2 & 0.1 \\
\hline FA30 & 30 & 70 & 14 & 75 & 50 & 30 & 2 & 0.1 \\
\hline S10 & 10 & 90 & 14 & 75 & 50 & 35 & 2 & 0.1 \\
\hline S20 & 20 & 80 & 14 & 75 & 50 & 32.5 & 2 & 0.1 \\
\hline $\mathrm{S} 30$ & 30 & 70 & 14 & 75 & 50 & 30 & 2 & 0.1 \\
\hline
\end{tabular}

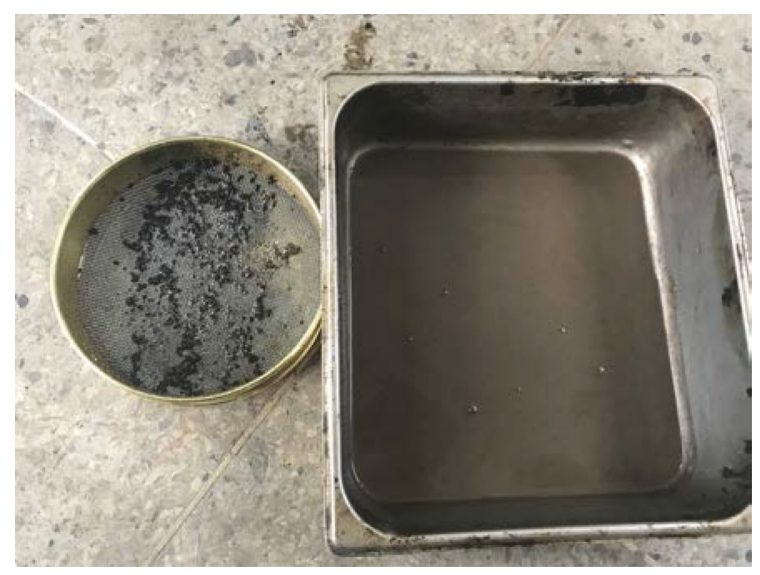

(a)

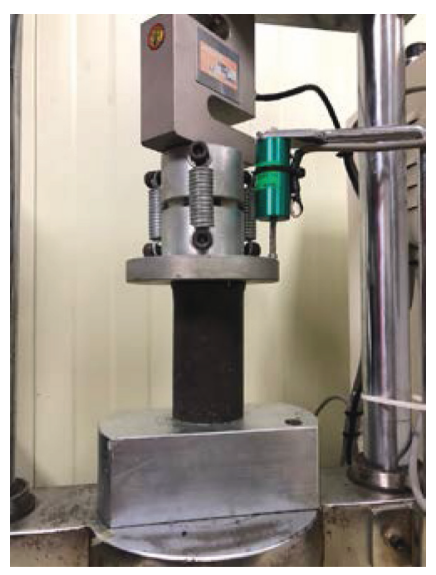

(b)

FIgURE 1: Mixing stability test (a) and UCS test (b).

TABle 4: Mix design for a new mixing stability test.

\begin{tabular}{|c|c|c|c|c|c|c|}
\hline Condition & Cementitious content (each $50 \mathrm{~g}$ ) & Asphalt emulsion (g) & Mixing & Residue sieving & Residue drying & Weighing \\
\hline $\mathrm{C}$ & Cement & 50 & & & & \\
\hline S & Slag & 50 & $3 \mathrm{~min}$ & & $24 \mathrm{~h}$ & \\
\hline FA & Fly ash & 50 & & & & \\
\hline
\end{tabular}

the workable time instead of the initial time. The differences between bleeding of the CAM mixture after the first 5 min and after workable time will be studied in further research. The bleeding water after the workable time is recorded by calculating the mass of bleeding water to the mass of the specimen:

$$
\text { bleeding }(\%)=\frac{M_{\mathrm{w}}}{M_{\mathrm{s}}} \times 100 \text {, }
$$

where $M_{\mathrm{w}}=$ mass of bleeding water and $M_{\mathrm{s}}=$ mass of the specimen.

2.5. Unconfined Compressive Strength Test. The UCS test was employed in this research to quantify the strength development of CAM, especially the cement hydration product [24]. After thorough mixing, the fresh material was cast into the precut paper mold $(\varnothing 50 \times 100 \mathrm{~mm})$. Although the CAM mixture can obtain the strength of about $0.35 \mathrm{MPa}$ after the first two hours, all 28-day strength samples are cured in the mold for 1 day before subjecting them to the unmolding process to ensure the shape stability of the sample. With regard to the curing condition, the environment was controlled at $95 \%$ relative humidity and $20^{\circ} \mathrm{C}$ until the testing day. In the UCS test, the universal compression machine with a loading rate of $1 \mathrm{~mm} / \mathrm{min}$ is employed to generate accurate test results. 3 replicates will be used to determine the average result of $1 \mathrm{mix}$ design (Figure 1(b)).

2.6. SEM Test. Under a high-vacuum condition, the Hitachi FE-SEM S-4700 was used to determine the microstructure of the 28-day strength CAM. Mixes F30, S30, and C were three mixtures employed and evaluated in this test. These mixtures 


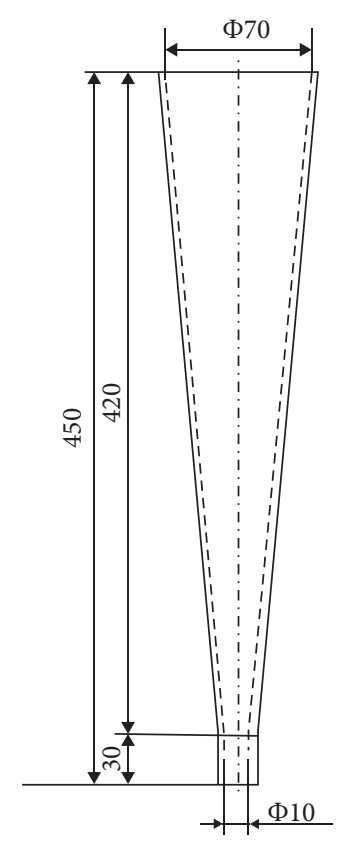

(a)

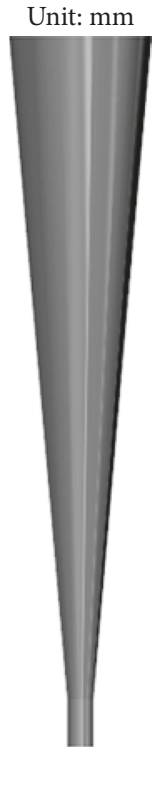

Figure 2: Flow cone funnel test (a) and flowability test (b). were expected to clearly display the main differences in SEM morphologies of CAM mixtures with slag or fly ash.

\section{Results and Discussion}

\subsection{Mixing Stability Test}

3.1.1. Mixing Stability Test on Normal Mixtures. The mixing stability test results of CAM mixtures are illustrated in Figure 3. The test results revealed that the lower residue content was recorded in mix FA and mix S. This can be attributed to the strong reaction of cement to the demulsification process of asphalt emulsion. The application of fly ash or slag will reduce the adsorption energy of cement to asphalt droplets in asphalt emulsion to some extent. For instance, when $30 \%$ of the cement content is replaced by fly ash, the residue content of the control mix reduced remarkably to nearly three times (from 3.15 to $1.15 \%$ ). A higher fly ash or slag content will protect the mixing stability of asphalt droplets in asphalt emulsion, thereby prolonging the demulsification process of the mixture. Evidently, the CAM particles formed in the fresh mixture with fly ash and slag obtain better homogeneous distribution.

It should be noted that fly ash may impose less energy adsorption to the asphalt droplets compared to slag. Consequently, the residual content of mixtures with fly ash is noticeably lower. At the same cement content substitution of $30 \%$, the residual content of mix FA30 and mix S30 is 1.15 and $1.75 \%$, respectively. This may be due to the $\mathrm{CaO}$ content in the fly ash mixture that is much lower than that in slag. The high $\mathrm{CaO}$ content in slag is nearly the same in cement that may accelerate the demulsification process of asphalt droplets at an early stage of fresh CAM paste (Table 1).

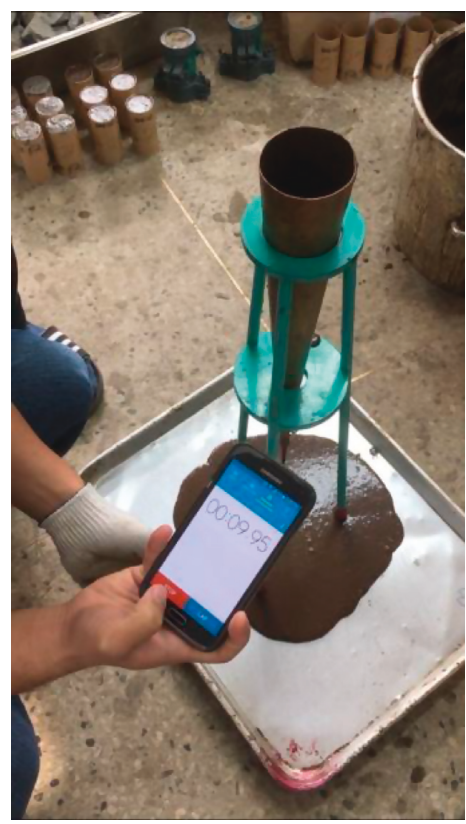

(b)

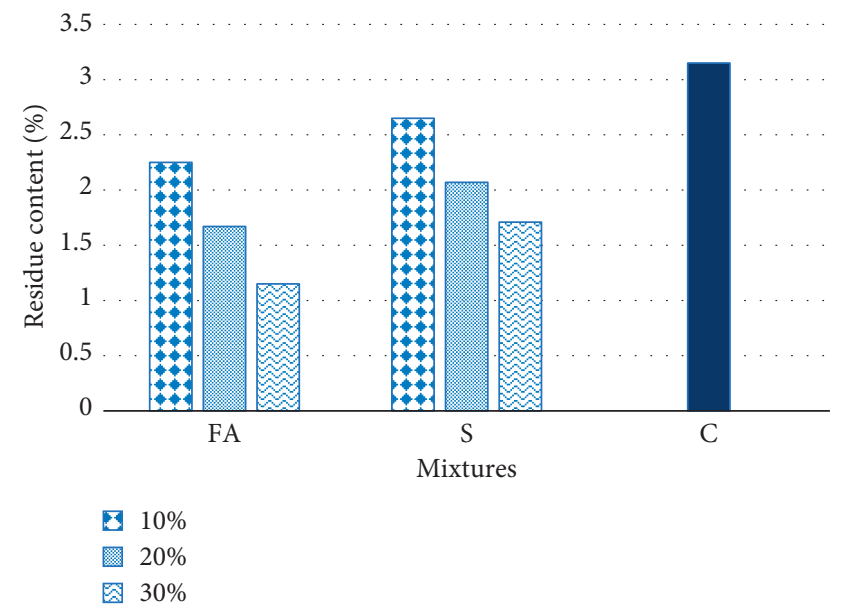

Figure 3: Mixing stability test results of normal mixtures.

3.1.2. Mixing Stability Test on the New Mixture (Only Cement (Slag/Fly Ash) with Asphalt Emulsion). As can be seen from Figure 4, the residual content of mixes FA, S, and C is $3.1 \%$, $5.3 \%$, and $7.6 \%$, respectively. Without support from water and sand layer, the mixtures are significantly suffering from the fast demulsification process of asphalt emulsion based on preliminary research [10-12]. However, the gaps between the residue contents of cement, slag, and fly ash can be observed. This test confirmed the results from the above normal mixing stability test. It can be concluded that cement imposes the strongest reaction to the asphalt droplets in asphalt emulsion followed by slag and then fly ash. Overall, reducing the cement content to proper values will not only ensure the stability of asphalt emulsion in the mixture but also propose a sustainable cost-effective method. 


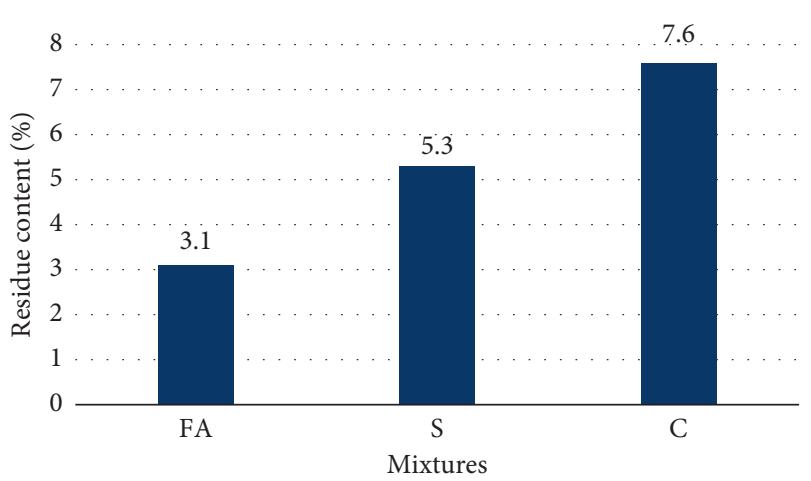

Figure 4: Mixing stability test results of new mixtures.

3.2. Flowability Test. Figure 5 presents the flowability of CAM mixtures. With the same AE, S, and W conditions, the replacement by fly ash or slag shortened the flow times of all conditions. The higher the cement replacement content, the faster the flow time. Mixtures with fly ash obtain a very good flow time value with mix FA30 having the fastest flow time of around $11 \mathrm{~s}$ (two times faster than that of mix C). The test results indicated that mixtures with slag and fly ash exhibited a rare sign of agglomeration at the nozzle of the flow cone. This may be due to the homogeneous CAM particles established when less cement is used. It can also be due to the unique spherical shape, beneficial size distribution, and chemical properties of fly ash or slag. The test results reassure the findings from the mixing stability test with a lower residue content recorded in mix FA and mix S. Hence, it can be concluded that the mixing stability is related to the demulsifying behavior during mixing, which may also affect the mechanical properties of hardened CA mortar [25]. Besides, the fast flow time value may impose a high bleeding phenomenon which triggers a slow setting time for the CAM mixture. Hence, the following bleeding test will determine this concern.

3.3. Bleeding Test. Figure 6 describes the bleeding problem of CAM mixtures with slag and fly ash. Based on preliminary research about the use of slag or fly ash $[14,17]$, it is expected that using by-products as a replacement for cement can mitigate the bleeding phenomenon issue. The test results show that slag and fly ash mixtures exhibit outstanding results with low signs of bleeding phenomenon. When cement contents are reduced in the fly ash or slag mixture, the bleeding value reduced sharply. For example, the bleeding values of mix C, mix S30, and mix FA30 are $1.75 \%, 0.86 \%$, and $0.66 \%$, respectively. It can be explained by the fast demulsification process of asphalt emulsion in the mixture with only cement. In this stage, asphalt droplets are coalesced, creating a continuous asphalt membrane which will cover the cement particle. The trapped water in asphalt emulsion will be extracted out, and it will cause a high bleeding value. Therefore, it is suggested to apply a proper amount of these mineral admixtures in the CAM mixture to reduce bleeding.

3.4. Workable Time Test. With regard to the workable time of CAM, Figure 7 shows the overall results of this property.

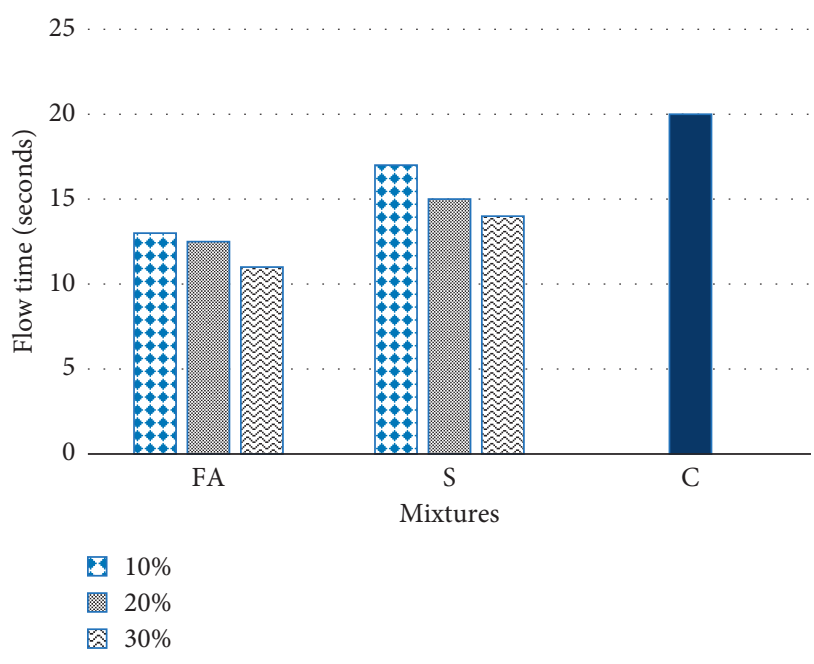

Figure 5: Flowability test results.

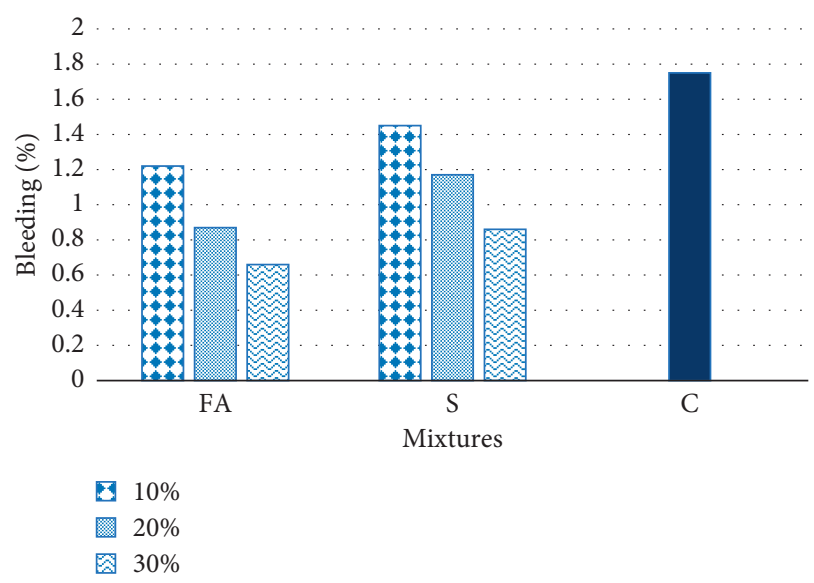

FiguRE 6: Bleeding test results.

In general, the addition of by-product generates a longer workable time for the CAM mixture.

When the FA or slag content is increased, the workable time of the CAM mixture is increased. As can be seen from Figure 7, the workable time of mix S30 is $75 \mathrm{~min}$ which is about two times higher than that of the control mix ( $30 \mathrm{~min})$. This may be due to the slow hydration rate of slag and fly ash compared to cement. Besides, the test results also indicated that adding slag provides better workable time for CAM mixtures compared to fly ash. For instance, mix FA10 maintained the optimum workable condition for around $40 \mathrm{~min}$, and meanwhile, mix S10 maintained it for 10 more minutes in this stage. The workable time shares a strong correlation with the early strength development of the CAM mixture. Slag mixtures had the longest workable time, and therefore, the CAM mixture with this by-product may suffer low early strength gain. This phenomenon will be justified in the succeeding 2-hour UCS test.

3.5. 2-Hour UCS Test. Figure 8 shows the 2-hour UCS test results of CAM mixtures with fly ash and slag. Due to the 


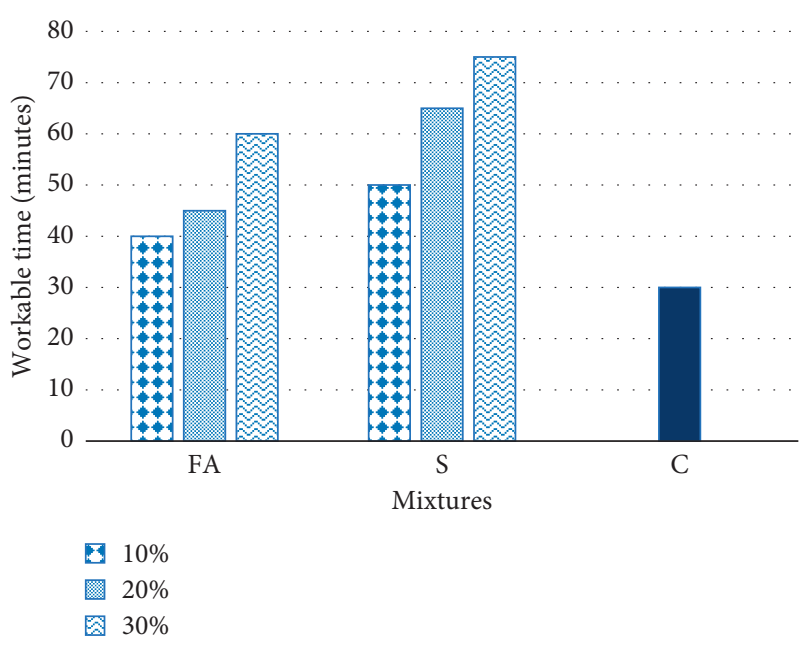

FIGURE 7: Workable time test results.

much longer workable time of the CAM mixture of fly ash or slag, those conditions obtained noticeably lower UCS compared to the controlled mixture. It can be concluded that the replacement of cement by fly ash and slag will prolong the overall setting time and retard the early strength gain of the CAM mixture. When $10 \%$ of the cement content was replaced by fly ash and slag, there was a critical drop in the strength of the CAM mixture with a UCS value of 0.28 and $0.26 \mathrm{MPa}$, respectively. This result agrees with the findings from other research about the impact of fly ash and slag on the UCS of cement mortar at an early age. Hence, the required time for actual application when using fly ash or slag in the CAM mixture should be taken into consideration.

As can be seen from Figures 7 and 8, the mixture with slag has a longer workable time compared to the mixture with fly ash. This result explains why the slag mixture has lower UCS compared to the mixture with fly ash after $2 \mathrm{~h}$. However, the differences in UCS between the two byproducts can be neglected. For example, at a cement replacement level of 30\%, mix FA30 has a UCS value of 0.19 compared to 0.17 of mix S30.

3.6. 28-Day UCS Test. The 28-day UCS test results of CAM mixtures with slag and fly ash are portrayed in Figure 9. Although both fly ash and slag mixtures share the same trend in strength at an early age, there is a reverse trend in strength development after 28 days.

At an early age, the mixture with fly ash has lower strength compared to the control mix, and it is interesting that the replacement of cement by this mineral admixture promotes a promising long-term strength achievement. A higher fly ash content leads to a higher strength gain after 28 days. It can be considered that the UCS of control mix and mix F30 is relatively the same (around 3.7 MPa). Because of the unique spherical shape, beneficial size distribution, and chemical properties of fly ash, the fly ash hydration product proposed a good connection with the asphalt membrane. The homogeneous distribution of asphalt droplets in the CAM mixture with fly ash also contributed to a uniformly

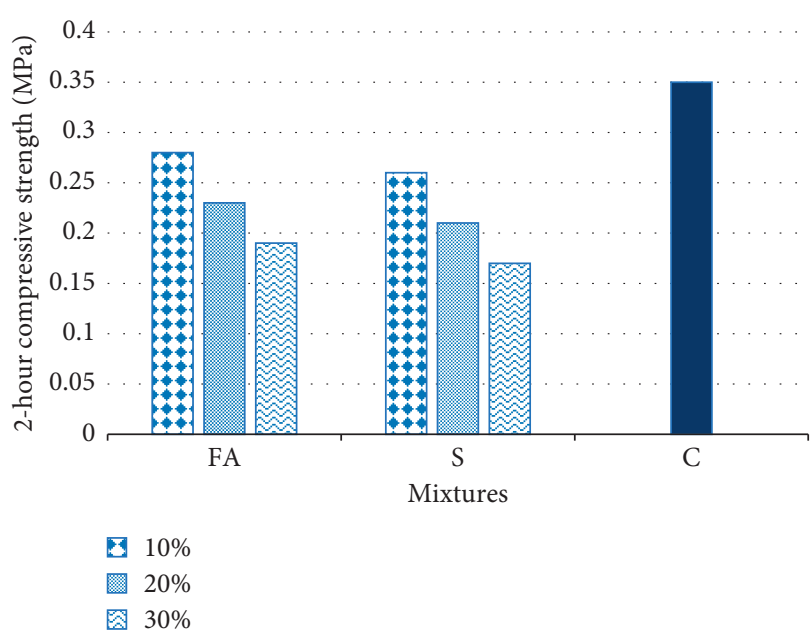

FIGURE 8: 2-hour unconfined compressive strength test results of CAM mixtures.

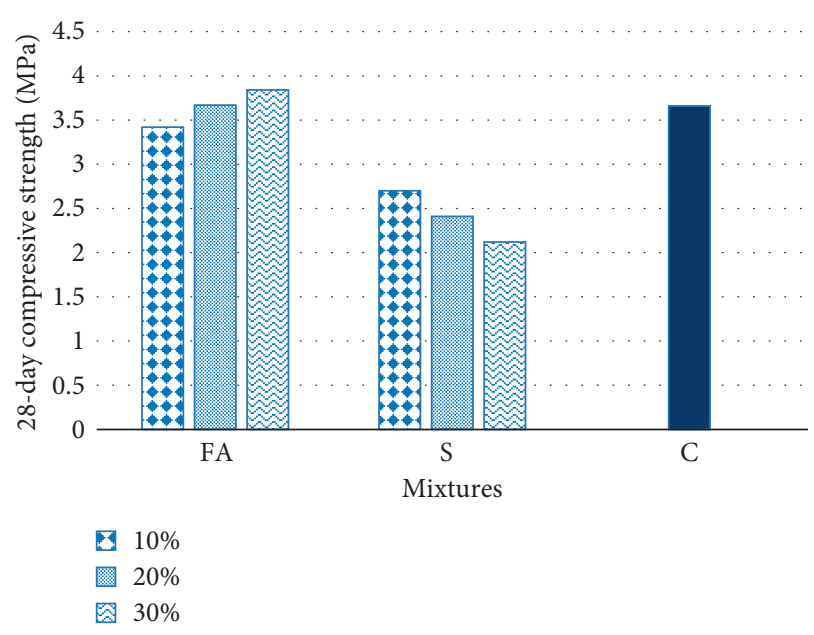

FIGURE 9: 28-day unconfined compressive strength test results of CAM mixtures.

structured formation. Moreover, based on related research about fly ash [14-17], the hydration process of this mineral admixture increases strength gradually through time with low hydration heat release. This mechanism of fly ash may help the CAM mixture build up a better strength-bearing structure with less chance of internal cracking and shrinkage. Hence, the application of fly ash in the CAM mixture not only utilizes the by-product material but also improves the overall mechanical properties of CAM in both fresh and hardened stages.

With regard to mixtures with slag, the slag mixture obtains ideal mixing stability with good flow time and workable time and the UCS results at both ages show poor values which indicated that the replacement of cement by slag does not contribute to the mechanical property of CAM. This may be because the pozzolanic reaction of CA mortar with slag is not effective. For example, there is a sudden drop in the UCS for the control mixture from $3.66 \mathrm{MPa}$ to 2.7 MPa when only $10 \%$ of the cement content is replaced by 


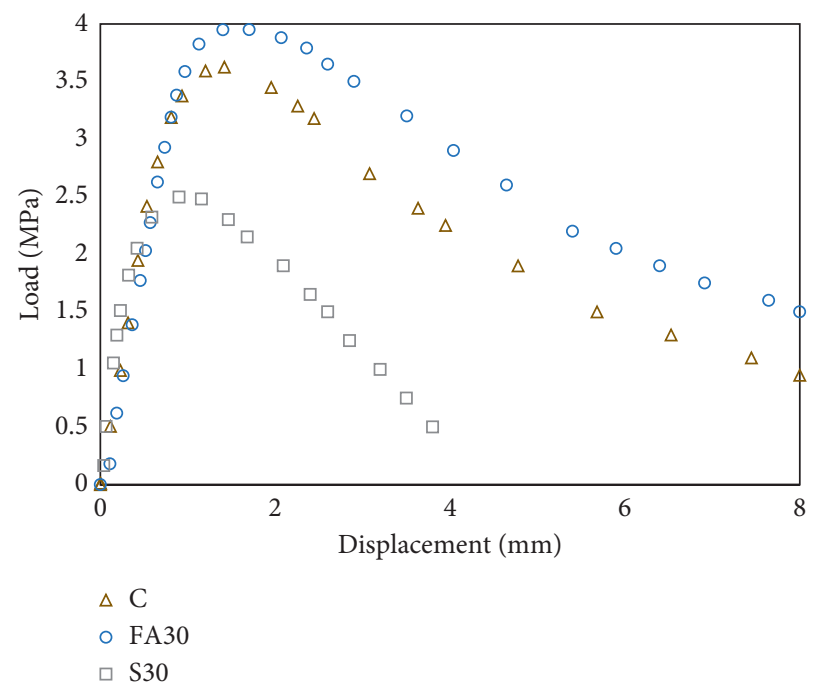

FIGURE 10: Load-displacement behavior of the CAM mixture after 28-day strength.

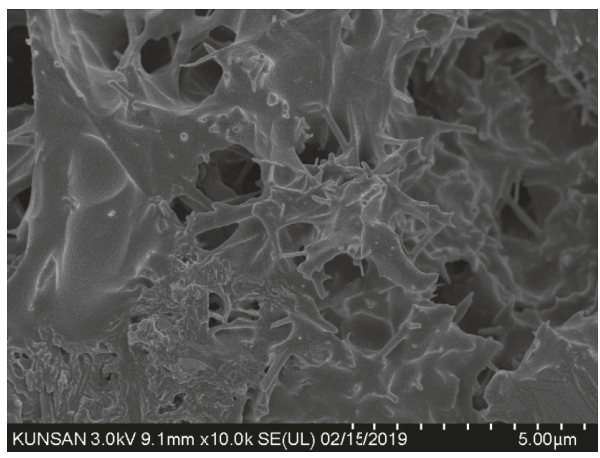

(a)

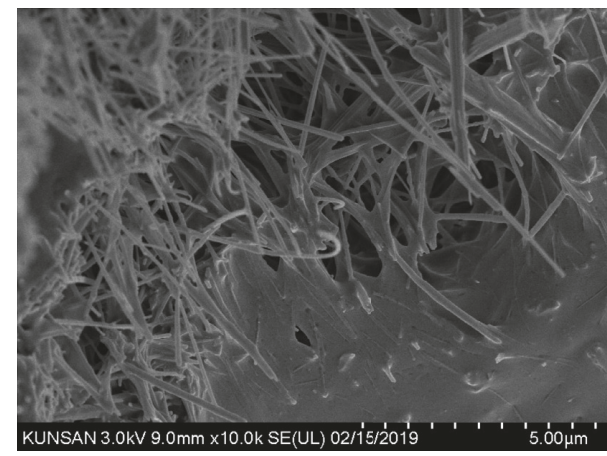

(b)

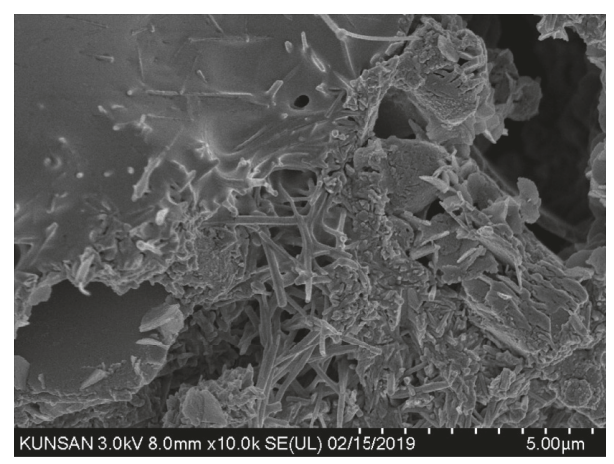

(c)

FIgUre 11: SEM test results of CAM mixtures: (a) mix FA30; (b) mix S30; (c) mix C.

slag. Therefore, although the application of slag in cement shows some promising results for the concrete mixture, this combination may otherwise impose critical effects on the production of CAM.

3.7. Load-Displacement Analysis. Figure 10 shows the loaddisplacement trends of CAM mixtures after 28 days. To identify the effect of fly ash or slag on this property of CAM, mix FA30, mix S30, and mix C are selected for comparison. It is obvious that mix C and mix FA30 share the same trend in load-displacement behavior. After reaching the peak stress, they appear to be ductile with a gradual decrease in strength until the failure point $[12,26]$. However, it can be seen that the performance of the CAM mixture with fly ash is relatively better than that of the controlled mixture. In general, it can be explained by the homogeneous distribution of CAM particles in the mixture with fly ash. The finer 
particle size of fly ash may propose a denser structure with thorough mixing condition between the cement hydration product and the asphalt membrane. Based on the mixing stability test results, the residue content of the cement mixture is higher than that of the fly ash mixture (FA30), and this may form bigger particle size with poor particle distribution. Also, the gradual increase in strength may contribute to better structure development in the fly ash mixture.

Regarding the CAM mixture with slag, mix S30 not only showed poor peak stress but also suffered from a steep drop in strength after this highest point. It may be attributed to the high $\mathrm{CaO}$ content of slag which accelerates the demulsification process of asphalt emulsion, thereby forming inhomogeneous particles and developing a poor structure.

3.8. SEM Analysis. The SEM analysis results of the CAM mixture with slag and fly ash are presented in Figure 11. To justify the conclusion from the load-displacement test, mix F30, mix S30, and mix C were employed in this analysis. In general, the findings from the SEM test reassured the UCS test results.

Based on related research [14-17], microstructural investigation of the asphalt binders with fly ash demonstrated crack-mitigating behavior of the spherical fly ash particles incorporated into the bitumen matrix. In this research, the FA mixture has the best homogeneous distribution of the asphalt membrane along with the hydration product material. From the SEM test, a dense structure between mixing components is developed with a low air void content (Figure 11(a)). This finding agrees with that of UCS and load-displacement test analysis which shows that the fly ash mixture obtained better ductile behavior after reaching peak load compared to mix C.

In the SEM of the mixture with slag shown in Figure 11(b), the hydration product has a poor connection with the asphalt membrane which is the reason why mix S30 obtained the lowest strength with a minor ductile behavior.

Regarding control mix, the hydration product of cement has acceptable bonding with the asphalt membrane. However, large air voids were observed in the mixture that may prove why mix $\mathrm{C}$ achieved lower strength and ductile performance compared to mix F30 (Figure 11(c)).

\section{Conclusions}

This study evaluates the potential of utilizing fly ash and slag in the production of CAM as a stabilization method for fouled ballast. By assessing the effect of these by-products on the mechanical properties of CAM, optimum mix formulation will be proposed to serve further research on the sustainable development of CAM. The following conclusions can be drawn from this manuscript:

(i) The replacement of cement by slag or fly ash improves the overall fresh properties of CAM, especially the mixing stability. The higher the cement by by-product replacement, the better the effectiveness.
This can be explained by the reduction of the strong reaction of cement particles to asphalt droplets in asphalt emulsion by using by-products.

(ii) The application of slag or fly ash to the CAM mixture does not only prolong the demulsification process of asphalt emulsion but also retard the hardening process of CAM.

(iii) After 28 days, the poor pozzolanic reaction in the slag mixture may result in the lowest strength gain compared to the remaining mixtures. Meanwhile, the 28-day UCS test shows promising results with the fly ash mixture, especially mix F30. Although the mixture with fly ash suffered from strength reduction compared to the control mix at an early age, the strength of this condition increases dramatically after 28 days.

(iv) The load-displacement behavior of the mixture with fly ash shows a higher ductile characteristic compared to the control mixture and slag mixture. This is attributed to the homogeneous distribution and proper bonding of the asphalt membrane along with the hydration products in mixtures with fly ash.

(v) SEM analysis also points out that the fly ash mixture is denser than the controlled mix. The air void systems in the fly ash mixture are relatively lower than those in the mixture with only cement. Based on the above ideal engineering properties, the CAM mixture with fly ash is suggested to be applied in further research as a cost-effective strategy.

\section{Data Availability}

The data used to support the findings of this study are available from the corresponding author upon request.

\section{Conflicts of Interest}

The authors declare that there are no conflicts of interest regarding the publication of this paper.

\section{Acknowledgments}

This research was supported by a grant (18RDRP-B07656405) from Regional Development Research Program funded by the Ministry of Land, Infrastructure, and Transport of the Korean Government.

\section{References}

[1] E. T. Selig and J. M. Waters, Track Geotechnology and Substructure Management, T. Telford, London, UK, 1994.

[2] J. Pires and A. G. Dumont, "Railway ballast degradation," in Proceedings of the 15th Swiss Transport Research Conference, Ascona, Switzerland, April 2015.

[3] G. D’Angelo, N. Thom, and D. L. Presti, "Bitumen stabilized ballast: a potential solution for railway track-bed," Construction and Building Materials, vol. 124, pp. 118-126, 2016.

[4] S. F. Brown, J. Kwan, and N. H. Thom, "Identifying the key parameters that influence geogrid reinforcement of railway 
ballast," Geotextiles and Geomembranes, vol. 25, no. 6, pp. 326-335, 2007.

[5] J. H. Kennedy, P. K. Woodward, G. M. Medero, and J. McKinney, "Full-scale cyclic geopavement \& railway accelerated fatigue testing," in Proceedings of the 10th International Railway Engineering Conference, London, UK, June 2009.

[6] Z. Leiben, X. Wang, Z. Wang, B. Yang, Y. Tian, and R. He, "Damping characteristics of cement asphalt emulsion mortars," Construction and Building Materials, vol. 173, pp. 201208, 2018.

[7] W. Qiang, Y. Peiyu, A. Ruhan, Y. Jinbo, and K. Xiangming, "Strength mechanism of cement-asphalt mortar," Journal of Materials in Civil Engineering, vol. 23, no. 9, pp. 1353-1359, 2011.

[8] J. Ouyang, L. Hu, H. Li, and B. Han, "Effect of cement on the demulsifying behavior of over-stabilized asphalt emulsion during mixing," Construction and Building Materials, vol. 177, pp. 252-260, 2018.

[9] Y. Tan, J. Ouyang, and Y. Li, "Factors influencing rheological properties of fresh cement asphalt emulsion paste," Construction and Building Materials, vol. 68, pp. 611-617, 2014.

[10] J. Ouyang, J. Zhao, and Y. Tan, "Modeling mechanical properties of cement asphalt emulsion mortar with different asphalt to cement ratios and temperatures," Journal of $\mathrm{Ma}$ terials in Civil Engineering, vol. 30, no. 10, article 04018263, 2018.

[11] T. H. M. Le, D.-W. Park, and J.-W. Seo, "Evaluation on the mechanical properties of cement asphalt mortar with quick hardening admixture for railway maintenance," Construction and Building Materials, vol. 206, pp. 375-384, 2019.

[12] T. H. M. Le, D. W. Park, and J. W. Seo, "Effect of water and emulsifier on the mechanical properties of cement asphalt mortar," MATEC Web of Conferences, vol. 271, article 03002, 2019.

[13] K. Sobolev, I. Flores, and J. D. Bohler, "Application of fly ash in asphalt concrete: from challenges to opportunities," in Proceedings of the World of Coal Ash Conference, St. Louis, MO, USA, May 2013.

[14] N. Longarini, P. G. Crespi, M. Zucca, N. Giordano, and G. Silvestro, "The advantages of fly ash use in concrete structures," Journal of the Polish Mineral Engineering Society, vol. 15, no. 2, pp. 141-145, 2014.

[15] S. C. K. Bendapudi and P. Saha, "Contribution of fly ash to the properties of mortar and concrete," International Journal of Earth Sciences and Engineering, vol. 04, no. 6, pp. 1017-1023, 2011.

[16] B. W. Ramme, A. Covil, A. Faheem, and K. Sobolev, "Fly ash-an important ingredient for use in hot-mix ashphalt concrete," in Proceedings of the Fourth International Conference on Sustainable Construction Materials and Technologies, Las Vegas, NV, USA, August 2016.

[17] K. V. Schuldyakov, L. Y. Kramar, and B. Y. Trofimov, "The properties of slag cement and its influence on the structure of the hardened cement paste," Procedia Engineering, vol. 150, pp. 1433-1439, 2016.

[18] D. Suresh and K. Nagaraju, "Ground granulated blast slag (GGBS) in concrete-a review," Journal of Mechanical and Civil Engineering, vol. 12, no. 4, pp. 76-82, 2015.

[19] J. Tao and X. Wei, "Effect of ground granulated blast-furnace slag on the hydration and properties of cement paste," Advances in Cement Research, vol. 31, no. 6, pp. 251-260, 2019.
[20] J. Q. Zuo, Q. B. Jiang, and B. F. Cai, "Experimental study on emulsified asphalt for CA mortar used in slab track," Railway Construction Technology, vol. 2, no. 2, pp. 68-70, 2005.

[21] KSM 2203, Emulsified Asphalt.

[22] KSF 2432, Testing Method for Consistency of Mortar Grouting.

[23] J. Ouyang, Y. Tan, D. J. Corr, and S. P. Shah, "The thixotropic behavior of fresh cement asphalt emulsion paste," Construction and Building Materials, vol. 114, pp. 906-912, 2016.

[24] KSF 2351, Testing Method for Compressive Strength of Asphalt Mixture.

[25] J. Ouyang, Y. Tan, D. J. Corr, and S. P. Shah, "Investigation on the mixing stability of asphalt emulsion with cement through viscosity," Journal of Materials in Civil Engineering, vol. 28, no. 12, article 04016149, 2016.

[26] J. Ouyang, B. Pan, W. Xu, and L. Hu, "Effect of water content on volumetric and mechanical properties of cement bitumen emulsion mixture," Journal of Materials in Civil Engineering, vol. 31, no. 6, article 04019085, 2019. 


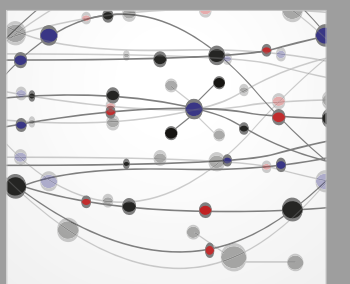

The Scientific World Journal
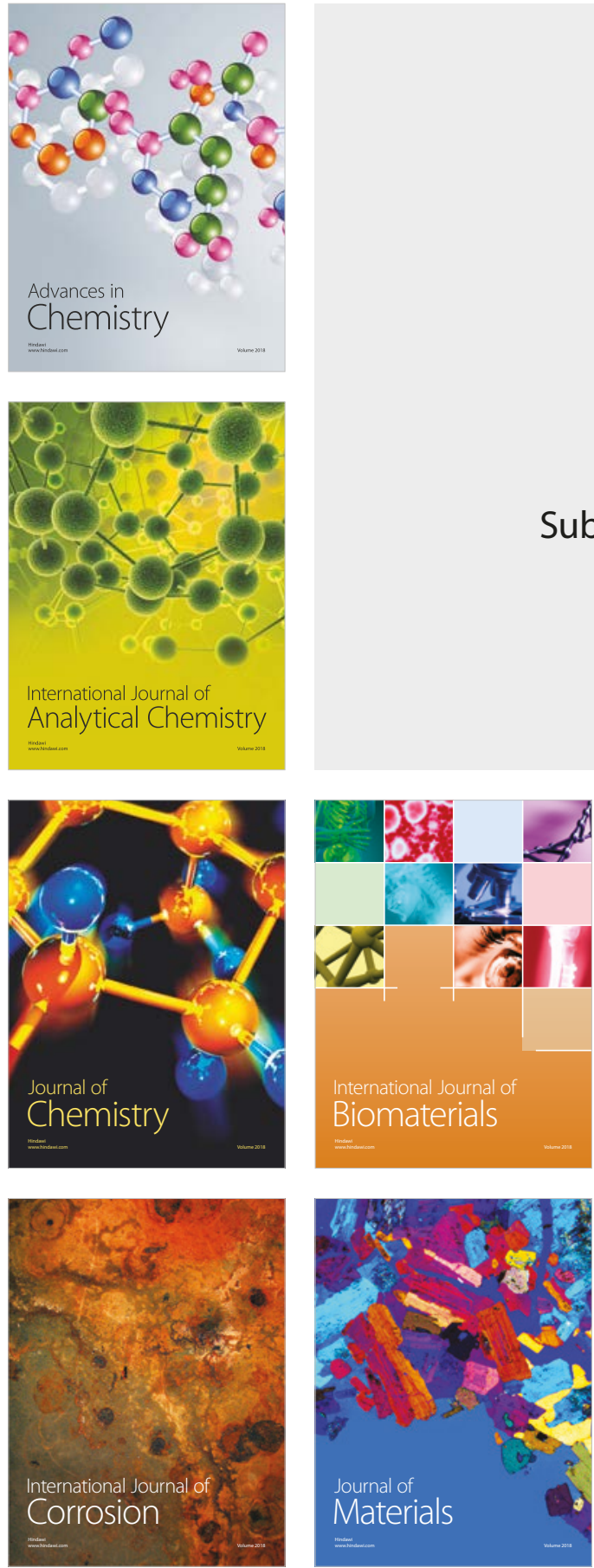

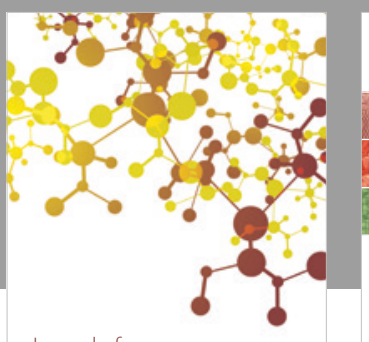

Journal of

Applied Chemistry
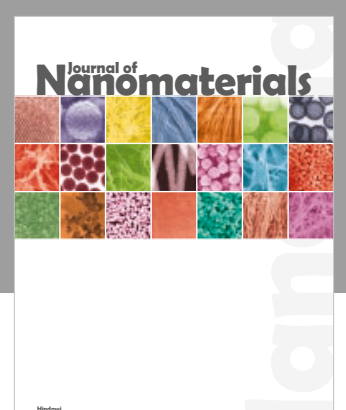

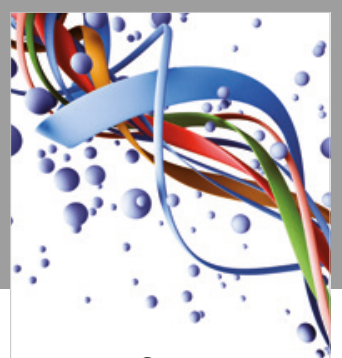

Scientifica

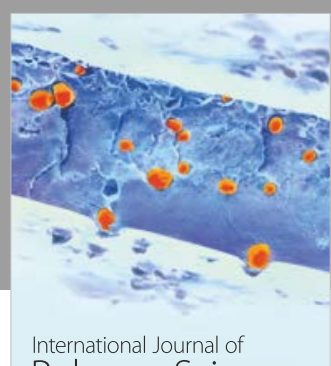

Polymer Science

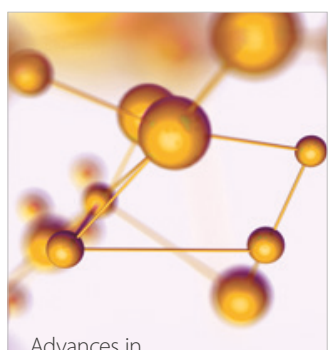

Physical Chemistry
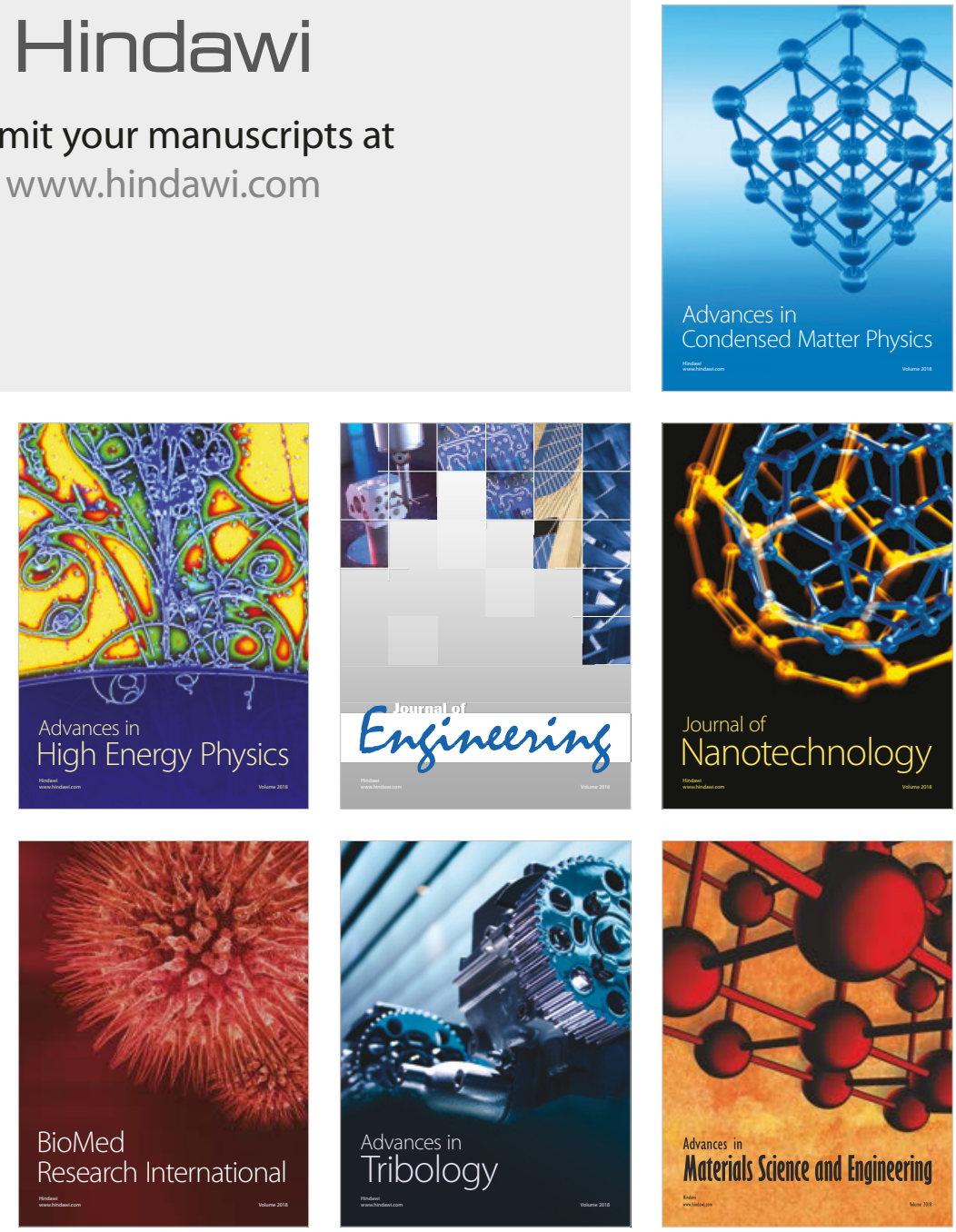